\title{
Comparison of Clonidine and Dexamedetomidine in Reduction of Pressor Response during Endotracheal Intubation- A Prospective Study
}

\author{
Hetal Sonavane', Parth Shah ${ }^{2}$ \\ ${ }^{1}$ Senior Resident, Department of Anaesthesia, Gujarat Cancer Research Institute, Ahmedabad, Gujarat, India, ${ }^{2}$ Senior Resident, Department of \\ Anaesthesia, GMERS Medical College, Himmatnagar, Gujarat, India.
}

\section{Abstract}

Background: Clonidine and dexmedetomidine have been used for attenuating sympathetic response to laryngoscopy and endotracheal intubation. Both these drugs have $\alpha-1$ and $\alpha-2$ receptors agonist activity but dexmedetomidine has selective $\alpha-2$ receptor agonist activity which helps to blunt sympathetic response to laryngoscopy and tracheal intubation. Present study was performed to compare the effect of single dose clonidine and dexmedetomidine in attenuating pressor response to laryngoscopy and intubation. Subjects and Methods: This was a prospective, randomized, controlled study on 68 adult patients aged between 18 and 65 years in American Society of Anesthesiologists (ASA) physical status I and II undergoing elective surgeries under general anesthesia. The patients were allocated randomly into two groups of 34 patients each group received as Group A [Clonidine group]: $1 \mu \mathrm{g} / \mathrm{kg}$ iv in $20 \mathrm{ml}$ normal saline over 10mins. Group B [Dexmedetomidine group]: $1 \mu \mathrm{g} / \mathrm{kgivin} 20 \mathrm{ml}$ normal saline over 10mins. Systolic blood pressure (SBP), Diastolic blood pressure (DBP), Mean arterial pressure (MAP), heart rate and $\mathrm{SpO} 2$ was noted after 5mins of drug administration, and again at the completion of study drug infusion. Results: There was no difference in HR, SBP, DBP\& MAP between the two groups during the infusion of study drug. After laryngoscopy and intubation, the mean HR, SBP, DBP \& MAP at 1st and 3rd minute was increased in Group A than Group B and it was statistically significant. Also, there was no significant difference between the mean HR of the two groups at 7th and 10th minute after intubation but group D had lower mean SBP, DBP \& MAP compared to group $\mathrm{C}$ which was significant. Conclusion: Preremedication with dexmedetomidine in dose has significantly attenuated the hemodynamic pressor responses to laryngoscopy and intubation when compared to clonidine.

Keywords: Clonidine, Dexmedetomidine, Laryngoscopy, Systolic blood pressure

Corresponding Author: Dr Parth Shah, Department of Anaesthesia, GMERS Medical College, Himmatnagar, Gujarat, India.

Received: September 2019

Accepted: September 2019

\section{Introduction}

Laryngoscopy and endotracheal intubation, which are a basic and integral part of general anesthesia (GA), are associated with reflex sympathetic stimulation, manifested by tachycardia and hypertension. ${ }^{[1]}$ This is known as pressor response and has the potential to cause major complications such as myocardial ischemia, ventricular arrhythmia, left ventricular failure, and cerebral haemorrhage. ${ }^{[2]}$ Usually these changes are well tolerated by healthy individuals, but may prove to fatal in patients with untreated severe hypertension, coronary artery disease or intracranial aneurysm. The circulatory response in the form of increased heart rate and raised blood pressure usually occurs for short duration and is unpredictable. This transient increase in blood pressure and pulse rate does not cause any harm in healthy individuals but may create problem in patients with myocardial insufficiency or cerebrovascular disease which may further cause complications like pulmonary oedema, myocardial infarction or cerebrovascular accidents. ${ }^{[3,4]}$
Various pharmacological methods are evaluated either in the premedication or during induction to attenuate these adverse hemodynamic responses of laryngoscopy and intubation, such as inhalational anesthetics, lidocaine, narcotic analgesics, topical anaesthetic, beta blockers, calcium channel blockers, ACE inhibitors and vasodilators but with variable results.

Clonidine and dexmedetomidine have been used for attenuating sympathetic response to laryngoscopy and endotracheal intubation. Both these drugs have $\alpha-1$ and $\alpha-2$ receptors agonist activity but dexmedetomidine has selective $\alpha-2$ receptor agonist activity which helps to blunt sympathetic response to laryngoscopy and tracheal intubation. Clonidine is clinically useful due to sympatholytic, hypnotic, analgesic, sedative and anxiolytic effect without respiratory depression. ${ }^{[5,6]}$

Present study was performed to compare the effect of single dose clonidine and dexmedetomidine in attenuating pressor response to laryngoscopy and intubation. 


\section{Subjects and Methods}

This was a prospective, randomized, controlled study on 68 adult patients aged between 18 and 65 years in American Society of Anesthesiologists (ASA) physical status I and II undergoing elective surgeries under general anesthesia after obtaining written informed consent from patients. The study was approved by institutional Ethics Committee. All the patients underwent a pre-anesthetic evaluation, which comprised of a detailed history taking, a clinical examination in either the anesthesia OPD or at the bed side and evaluation of the investigations. Pregnant and nursing woman, patient with morbid obesity, having underlying cardiovascular or other systemic disease, diabetes, taking any non-permitted medications or known allergic to study medications were excluded.

The anaesthesiologist administering drug and evaluating the patient was blinded to the drug injected. Randomization done by computer generated table. The patients were allocated randomly into two groups of 34 patients each group received as

Group A [Clonidine group]: $1 \mu \mathrm{g} / \mathrm{kg}$ iv in $20 \mathrm{ml}$ normal saline over 10mins.

Group B [Dexmedetomidine group]: $1 \mu \mathrm{g} / \mathrm{kgivin} 20 \mathrm{ml}$ normal saline over 10mins.

Both the drugs were infused through syringe infusion pump. Systolic blood pressure (SBP), Diastolic blood pressure (DBP), Mean arterial pressure (MAP), heart rate and $\mathrm{SpO} 2$ was noted after 5mins of drug administration, and again at the completion of study drug infusion i.e. after $10 \mathrm{mins}$ of drug administration. SBP, DBP, MAP, Heart rate, SpO2 were noted at $1 \mathrm{st}$ (AI 1st min), 3rd (AI 3rd min), 5th (AI 5th min), 7th (AI 7th min) \& 10th minute after laryngoscopy \& intubation.

Anaesthesia was maintained on $\mathrm{N} 2 \mathrm{O}+\mathrm{O} 2$, Isoflurane, Vecuronium and analgesics. IV fluids were administered as per requirement. At the end of surgical procedure, patients were reversed and extubated uneventfully. After clinical recovery patients were shifted to recovery room and observed for 2 hrs for nausea, vomiting, bradycardia, hypotension, \& sedation. After assessing the Ramsay sedation score, patients were shifted to the ward and followed for another 24 hours; side effects if any were treated \& recorded.

\section{Statistical analysis:}

The recorded data was compiled and entered in a spreadsheet computer program (Microsoft Excel 2007) and then exported to data editor page of SPSS version 15 (SPSS Inc., Chicago, Illinois, USA).

Descriptive statistics included computation of percentages, means and standard deviations. The statistical tests applied for the analysis were Pearson's chi-square test $\left(\chi^{2}\right)$, t-test, One way Analysis of Variance and Stepwise multiple linear Regression analysis. For all tests, confidence level and level of significance were set at $95 \%$ and $5 \%$ respectively.

\section{Results}

The demographic profiles of the patients were comparable in respect of age, sex, weight and ASA physical status. None of the demographic data was significant compared in both groups. [Table 1]

The mean dose of thiopentone sodium $(\mathrm{mg} / \mathrm{kg})$ required for loss of eye lash reflex in group A and group B were $4.99 \pm 0.3$ and $4.1 \pm 0.1$ respectively and it was significant statistically. $(\mathrm{p} \leq 0.05)$

There was no difference in HR, SBP, DBP\& MAP between the two groups during the infusion of study drug. After laryngoscopy and intubation, the mean HR, SBP, DBP \& MAP at 1st and 3rd minute was increased in Group A than Group B and it was statistically significant. $(\mathrm{p} \leq 0.05)$ At $1 \mathrm{st} \&$ 3rd minute HR increased by $11 \%$ and $4.9 \%$ in Group A \& $2.1 \%$ at 1 st minute in Group B. In Group A at 1 st\& 3rd minute SBP increased by $12 \%$ \& $6 \%$, DBP increased by $15 \%$ $\& 8 \%$ and MAP by $14 \%$ and $5.9 \%$, while Dexmedetomidine group showed no statistical significant difference between the baseline value and $1 \mathrm{st}$ and $3 \mathrm{rd}$ minute. Also, there was no significant difference between the mean HR of the two groups at 7 th and 10th minute after intubation but group D had lower mean SBP, DBP \& MAP compared to group C which was significant.

In clonidine group, none of the patients had side effects like bradycardia and hypotension. In group B, one patient had developed hypotension at third minute after intubation which was managed by decreasing inhalational agent and infusing intravenous fluids without inotropic support.

\begin{tabular}{|l|l|l|l|}
\hline Table 1: Comparison of Demographic variables in Both Groups \\
\hline Variable & $\begin{array}{l}\text { Group A } \\
(\mathbf{m e a n} \pm \mathbf{s d})\end{array}$ & $\begin{array}{l}\text { Group B } \\
(\mathbf{m e a n} \pm \mathbf{s d})\end{array}$ & P value \\
\hline Age in years & $31.45 \pm 09.74$ & $35.12 \pm 11.52$ & 0.21 \\
\hline Gender (M/F) & $19 / 15$ & $16 / 18$ & 0.07 \\
\hline Height $(\mathrm{cm})$ & $157.41 \pm 8.3$ & $155.32 \pm 7.20$ & 0.10 \\
\hline Weight $(\mathrm{kg})$ & $54.12 \pm 6.18$ & $52.47 \pm 6.32$ & 0.32 \\
\hline ASA (I/II) & $25 / 9$ & $29 / 5$ & 0.09 \\
\hline
\end{tabular}

\section{Discussion}

The endotracheal intubation and laryngoscopy were associated with a rise in plasma catecholamine concentration and subsequent increase in the blood pressure, HR and the cardiac dysrhythmias. These above-mentioned effects may have serious repercussions on the high-risk patients like those with cardiovascular disease, increased intracranial pressure, or anomalies of the cerebral vessels. Attenuation of such responses is of great importance in the prevention of the perioperative morbidity and the mortality. ${ }^{[7]}$ The hemodynamic response to laryngoscopy and endotracheal intubation has been a topic of discussion since 1940, when Reid and Brace found that the stimulation of the upper respiratory tract provoked an increase in the vagal activity. ${ }^{[8]}$ A year later, Burstein et al, ${ }^{[9]}$ totally contradicting Reid's statement, found that the pressor response was due to an augmented sympathetic activity, which was provoked by the stimulation of the epipharynx and the laryngopharynx, which was further confi rmed by Prys-Roberts. ${ }^{[10,11]}$

In view of demographic criteria and surgery both groups were comparable. In our study dose of clonidine and dexmedetomidine were used at dose of $1 \mathrm{ug} / \mathrm{kg}$ intravenously which based on observation in previous studies. Various 
studies have been carried out with intravenous clonidine and dexmedetomidine to blunt stress response like tachycardia, hypertension to laryngoscopy and endotracheal intubation with various doses.

Clonidine $1 \mathrm{mcg} / \mathrm{kg}$ iv attenuate haemodynamic response of laryngoscopy and endotracheal intubation. Dexmedetomidine $1 \mathrm{mcg} / \mathrm{kg}$ iv also attenuate stress response to laryngoscopy and endotracheal intubation in CABG patients. When clonidine and dexmedetomidine used in dose $1 \mathrm{mcg} / \mathrm{kg}$ iv and compared, both showed significant reduction in myocardial contractility during laryngoscopy and intubation. ${ }^{[12]}$ In our study clonidine and dexmedetomidine in dose $1 \mathrm{ug} / \mathrm{kg}$ diluted to $20 \mathrm{ml}$ with normal saline and given intravenously over a period of $10 \mathrm{~min}$. Mean dose of thiopentone sodium used for induction with clonidine was $4.99 \pm 0.3$ while it was $4.1 \pm 0.1$ with dexmedetomidine, which is statistically highly significant. So, there is significant reduction in thiopentone sodium requirement was seen in dexmedetomidine group compared to clonidine group. Dexmedetomidine is having anaesthetic sparing effect because of decrease in central noradrenergic transmission and specific $\alpha-2$ mediated analgesic and sedative property. Saoyroolu AE, et al. ${ }^{[13]}$ compared the clinical effects of two different doses of Dexmedetomidine $(1 \mu \mathrm{g} / \mathrm{kg}$ and $0.5 \mu \mathrm{g} / \mathrm{kg})$ on hemodynamic responses of tracheal intubation and concluded that Dexmedetomidine in dose of $1 \mu \mathrm{g} / \mathrm{kg}$ was more effective than dexmedetomidine $0.5 \mu \mathrm{g} / \mathrm{kg} .{ }^{[14]}$

It was observed that mean SBP, DBP and MAP in the dexmedetomidine group remained close to the baseline throughout the study period showing a significant difference from clonidine groups following the induction interval. In present study after intubation heart rate, SBP, and DBP is increased in all patients but the increase was more in patients of clonidine group when compared to dexmedetomidine group. There was statistically significant difference in heart rate between the two groups at 1,3 and 4 min interval after intubation ( $p$ value<0.05). No significant changes in peripheral oxygen saturation $(\mathrm{SpO} 2)$ and cardiac rhythm (ECG) were observed in any patients of both groups. A similar observation was made by Yildiz, et al. (2006). ${ }^{[15]}$ in some studies, it is observed that MAP was decreased by low dosage of dexmedetomidine $(0.25 \mu \mathrm{g} / \mathrm{kg})$ and MAP was increased transiently, and HR was decreased significantly by high dosage of $(1-4 \mu \mathrm{g} / \mathrm{kg})$ dexmedetomidine. Scheinin, et al. ${ }^{[15]}$ reported that the use of $\alpha 2$-agonist leads to bradycardia. Belleville, et al. 16 found that the dexmedetomidine given in $2 \mathrm{~min}$ in the doses of $1-2 \mu \mathrm{g} / \mathrm{kg}$ causes irregular ventilation and apnea episodes. Ebert, et al. ${ }^{[14]}$ did not observe any episode of apnea, airway obstruction and hypoxemia with bolus doses of dexmedetomidine in their study, and they reported that the depression of respiration may be seen due to deep sedation, for the reason that the $\alpha 2$ adrenergic agonists don't have an active role on the respiration center. Yildiz M, et al. ${ }^{[17]}$ and Varshali $\mathrm{M} \mathrm{K}$, et al. ${ }^{[18]}$ studied the effect of dexmedetomidine on hemodynamic response to laryngoscopy and intubation and intraoperative anesthetic requirement. They concluded that increase in blood pressure and heart rate were significantly less in dexmedetomidine group.

In clonidine group, no side effects were observed. One patient in group B had developed hypotension at 3rd minute after intubation; which was managed by decreasing inhalational agent, and infusing intravenous fluid without inotropes. Bajwa $\mathrm{S}$ et al suggested that cardiac side effects of dexmedetomidine like bradycardia and sinus pause could have warranted the use of atropine. Panda BK cleared that clonidine and dexmedetomidine does not cause any serious side effect.

\section{Conclusion}

Preremedication with dexmedetomidine in dose has significantly attenuated the hemodynamic pressor responses to laryngoscopy and intubation when compared to clonidine. Dexmedetomidine provided more stable hemodynamics during induction, laryngoscopy and intubation and is proved to be a better drug for premedication during general anesthesia.

\section{References}

1. Kanchi M, Nair HC, Banakal S, Murthy K, Murugesan C. Haemodynamic response to endotracheal intubation in coronary artery disease: Direct versus video laryngoscopy. Indian J Anaesth., 2011; 55: 260-5.

2. Vyankatesh JS, Ramesh VD, Jamadar NP, Patil BM, Vikram S. Attenuation of cardiovascular responses to laryngoscopy and endotracheal intubation: Comparative evaluation of clonidine and lignocaine. IJBAMR, 2012; 1: 313-23.

3. Prys-Roberts C, Green LT, Meloche R, Foex P. Studies of anaesthesia in relation to hypertension II. Haemodynamic consequences of induction and endotracheal intubation. Br J Anaesth 1971;43:531-47.

4. Dalton B, Guiney T. Myocardial ischemia from tachycardia and hypertension in coronary heart disease - Patients undergoing anaesthesia. Boston: Ann Mtg American Society of Anaesthesiologists 1972. pp. 201-2.5.

5. Jamadarkhana S, Gopal S. Clonidine in adults as a sedative agent in the intensive care unit. J Anaesthesiol Clin Pharmacol 2010;26:439-45.

6. Aho M, Lehtnen AM, Erkola O, Scheinin H, Lehtinen A, Kallio A, et al. The effect of intravenously administered dexmedetomidine on perioperative haemodynamics and isoflurane requirements in patients undergoing abdominal hysterectomy. Anaesthesiology. 1991;74:9971002.

7. Tryba M, Gehling M.Clonidine: A potent analgesic adjuvant. Curr Opin Anaesthesiol 2002;15:511-7.

8. Reid LC, Brace DE. Irritation of the respiratory tract and its refl ex effect upon heart. Surg Gynecol Obstet. 1940;70:157-62.

9. Burstein CL, Lopinto FJ, Newman W. Electrocardiographic studies during endotracheal intubation. I. Effects during usual routine technics. Anesthesiology. 1950;11(2):224-37.

10. Prys-Roberts C, Greene LT, Meloche R, Foëx P. Studies of anaesthesia in relation to hypertension. II. Haemodynamic consequences of induction and endotracheal intubation. Br J Anaesth. 1971;43(6):53147.

11. Prys-Roberts C, Foëx P, Biro GP, Roberts JG. Studies of anaesthesia in relation to hypertension. V. Adrenergic betareceptor blockade. $\mathrm{Br} \mathrm{J}$ Anaesth. 1973;45(7):671-81.

12. Panda BK, Singh $P$, Marne $S$, etal. A comparison study of Dexmedetomidine Vs Clonidine for sympathoadrenal response perioperative drug requirements and cost analysis.asian pacific journal of tropical disease. 2012:1-6.

13. Saoyroolu E, Celik, rhon, zer S, Sen B. Different doses of dexmedetomidine on controlling hemodynamic responses to tracheal intubation. The Internet Journal of Anesthesiology, 2010; $27: 2$.

14. Ebert TJ, Hall JE, Barney JA, Uhrich TD, Colinco MD. The effects of increasing plasma concentrations of dexmedetomidine in humans. Anesthesiology, 2000; 93: 382-94.

15. Scheinin B, Lindgren L, Randell T, Scheinin H, Scheinin M. Dexmedetomidine attenuates sympathoadrenel responses to tracheal intubation and reduces the need for thiopentone and peroperative fentanyl. Br J Anaesth., 1992; 68: 126-31. 
16. Belleville JP, Ward DS, Bloor BC, Maze M. Effects of intravenous dexmedetomidine in humans. I. Sedation, ventilation, and metabolic rate. Anesthesiology, 1992; 77: 1125-33.

17. Yildiz M, Tavlan A, Tuncer S, Reisli R, Yosunkaya A, Otelcioglu S. Effect of dexmedetomidine on hemodynamic responses to laryngoscopy and intubation: perioperative hemodynamics and anesthetic requirements. Drugs R D., 2006; 7: 43-52.

18. Varshali MK, Sushma L, Ramesh Naphade. Dexmedetomidine attenuates the sympathoadrenal response to tracheal intubation and reduces perioperative anaesthetic requirement. Ind J Anesth., 2011; 55: $352-7$.

Copyright: (c) the author(s), publisher. Academia Anesthesiologica International is an Official Publication of "Society for Health Care \& Research Development". It is an open-access article distributed under the terms of the Creative Commons Attribution Non-Commercial License, which permits unrestricted non-commercial use, distribution, and reproduction in any medium, provided the original work is properly cited.

How to cite this article: Sonavane H, Shah P. Comparison of Clonidine and Dexamedetomidine in Reduction of Pressor Response during Endotracheal Intubation- A Prospective Study. Acad. Anesthesiol. Int. 2019;4(2):218-221.

DOI: dx.doi.org/10.21276/aan.2019.4.2.50

Source of Support: Nil, Conflict of Interest: None declared. 